\title{
Spatial analysis of incidence of cutaneous melanoma in the Friuli Venezia Giulia region in the period 1995-2005
}

\author{
Lorenzo Cecconi, ${ }^{1}$ Anna Busolin, ${ }^{2}$ Fabio Barbone, ${ }^{3}$ Diego Serraino, ${ }^{4}$ Alessandra Chiarugi, ${ }^{5}$ \\ Annibale Biggeri, ${ }^{1,5}$ Dolores Catelan ${ }^{1,5}$ \\ ${ }^{1}$ Department of Statistics, Computer Science, Applications, University of Florence, \\ Florence; ${ }^{2}$ Epidemiological Service of Friuli Venezia Giulia, Trieste; ${ }^{3}$ Institute of Hygiene \\ and Clinical Epidemiology, University of Udine, Udine; ${ }^{4}$ Epidemiology Unit, Aviano Cancer \\ Center, Aviano; ${ }^{5}$ Institute for Study and Cancer Prevention, Florence, Italy
}

\begin{abstract}
Incidence distribution of cutaneous melanoma depends on phenotypic characteristics of population and geographic location. In Italy, in the period 1999-2003 Friuli Venezia Giulia (FVG) region had the second highest incidence rates for males and the third for females. We analysed melanoma and lip cancer incidence data of the FVG cancer registry for the period 1995-2005. We used Bayesian hierarchical spatial models to describe the spatial pattern by gender. We decomposed the geographical distribution of the risk in two parts: a component linked to chronic exposure and a component related to intermittent exposure. In order to model the chronic component we considered the geographical distribution of incidence cases of lip cancer, for which chronic occupational solar radiation exposure is a documented risk factor. We also analysed the distribution by site and we calculated standardised rates for body surface area. This study documents a significant gradient in the incidence of cutaneous melanoma in FVG. High-
\end{abstract}

Correspondence: Lorenzo Cecconi, Department of Statistics, Computer Science, Applications G. Parenti, University of Florence, viale Morgagni 59, 50134 Florence, Italy.

Tel. +39.0552.751500 - Fax: +39.0554 .223560 .

E-mail: cecconi@disia.unifi.it

Key words: Cutaneous melanoma; Skin cancer; Hierarchical Bayesian models; Spatial analysis.

Acknowledgements: the authors would like to gratefully acknowledge the scientific support of the Master in Epidemiology of the University of Turin, Turin, Italy.

Received for publication: 12 October 2015.

Accepted for publication: 12 October 2015.

CC Copyright L. Cecconi et al., 2016

Licensee PAGEPress, Italy

Geospatial Health 2016; 11:422

doi:10.4081/gh.2016.422

This article is distributed under the terms of the Creative Commons Attribution Noncommercial License (CC BY-NC 4.0) which permits any noncommercial use, distribution, and reproduction in any medium, provided the original author(s) and source are credited. standardised incidence rates are present in the area of Trieste and in the coastal area. The descriptive analysis by age group and by site, showed risks associated with intermittent exposures in both genders. For the coastal area the risk is especially high for sites traditionally linked to high cumulative exposures (face and neck), especially among men. The results suggest diagnostic preventive interventions in the populations living in the area of Trieste, given the high rates observed in the young age groups.

\section{Introduction}

Incidence distribution of cutaneous melanoma depends on phenotypic characteristics of population, in particular on the degree of pigmentation of the skin and the extent of solar radiation to which the people are exposed. The highest incidence rates are registered in population of Anglo-Saxon origin of Australia, New Zealand and North America, followed by people of northern Europe and those from Israel. Low frequencies are observed in southern Europe and of course, given the phenotypic characteristics, in African population (Mackay et al., 2006).

In Italy data from cancer registries (AIRTUM, 2009) showed for the period 2003-2005, an incidence ratio between North and South for cutaneous melanoma between 1.5 and 2. As in many Western Countries, the temporal trend has been increasing in the last ten years, while the death rate has remained substantially stable.

Data on cutaneous melanoma of the Cancer Registry of Friuli Venezia Giulia (FVG) region showed that in the period 1999-2003 FVG had the second highest incidence rates for males (after Turin) and the third for women (after Turin and Alto Adige) in Italy. Bidoli et al. (2007) reported an incidence rate of 14.5 per 100,000 in men and 14.2 per 100,000 for women, compared with a rate of 10 per 100,000 for the pool of Italian cancer registries. The main risk factors of cutaneous melanoma are well known in the literature: pattern of exposure to the sun (intensity, duration and mode of exposure), phenotype (the degree of skin pigmentation) and the predisposition to type melanocytic skin lesions such as nevi (Adami et al., 2002).

The site distribution is connected to the pattern of exposure to sunlight (continuous vs intermittent) (Lee et al., 1970; Green, 1992; Armstrong and Kricker, 1996) and, potentially, to the different response of melanocytes. This suggests specific causal mechanism for each site (Franceschi et al., 1996; Maldonado et al., 2003; Rivers, 2004; Whiteman et al., 1998, 2003). The analysis of the site distribution, however, must take into account for the body surface area (Pearl and Scott, 1986). 
Epidemiological literature reported for men values between 1.7 per 100,000 unit area (lower limb) and 20.7 (face excluded ear) in Canada (1969-1988), 7.7 and 59.3, respectively, in New Zealand (1968-1990 with the exception of 1979). For women, respectively, between 3.9 (trunk) and 19.3 (face) in Canada, and between 9.3 (trunk) and 62.3 (face) in New Zealand (Bulliard et al., 1997; Bulliard, 2000).

Over time, there has been an evolution of site distribution. For example in Sweden in the period 1960-1964 the rates per 100,000 unit area were 1.0 (men) and 4.0 (women) for the lower limb and 2.8 and 1.5 respectively for the trunk. In the period 2000-2004 the values were 4.8 (men) and 15.8 (women) for the lower limb and 23.0 (men) and 13.0 (women) for the trunk, always to 100,000 units surface (our calculations from Dal et al., 2007). Recently, a prospective multicentre study (Chiarugi et al., 2015) was carried out in Italy in order to assess the preferential development of melanoma in chronically or intermittently sun-exposed areas and the relationship between body site distribution. They found higher density ratio for shoulder and the back (2.03 and 2.14 , respectively). More melanomas than expected were also observed on the face and anterior neck (1.20 and 1.25).

Comparison of site distributions based on standardised rates is usually done using the concept of relative tumour density (Pearl and Scott, 1986) since they depend on the baseline rate. Bulliard et al. (1997) for example, compared New Zealand and Canada, and found quite similar density ratios even if those countries have different entities of solar radiation: 3.92 and 4.35 for the face in men, 3.04 and 3.64 for the lower limb in women, 0.51 and 0.35 for the trunk in men, 0.45 and 0.74 for the trunk in women. In Switzerland in the years 1995-2002 density ratios are 3.72 (men) and 5.60 (women) for the face, 0.38 (men) for the lower limb and 0.69 (women) for the trunk (our elaboration of Bulliard et al., 2007). The supposed greater frequency of melanomas of the trunk (site on intermittent exposure) reported from Sweden authors in recent years remains open, given that it has not be confirmed from calculations on the Swiss data.

The aim of this work is to study the geographical distribution of incidence of cutaneous melanoma in the period 1995-2005 in FVG (North Italy). We used Bayesian hierarchical spatial models to describe the spatial pattern in male and female. High cumulative exposures and chronic exposures occur with high rates of incidence in older age groups, reflecting a pathogenesis with long latency. The intermittent exposure (history of sunburn especially in childhood) gives rise to a high incidence rates among the younger people. We had therefore decomposed the geographical distribution of the risk in two parts: a component linked to chronic exposure and a component related to intermittent exposure. In order to model the chronic component we considered the geographical distribution of lip cancer, for which chronic occupational solar radiation exposure is a documented risk factor (Moore et al., 1999). Ecological regression analysis completes this part.

We also analysed the distribution by site and calculated standardised rates for body surface area and density ratios. The analysis by site is designed to assess whether the geographic differences are mainly attributable to typical sites of intermittent or chronic exposures.

\section{Data}

\section{Incidence data}

Incident cases from 1995 to 2005 were provided by the FVG cancer registry. The cases with ICD-IX 172, or ICD-X C43, were selected for a total of 2402 melanoma incident cases: 19 melanoma in situ were excluded, leaving 2383 cases for analysis of invasive cutaneous melanoma. Among these, 224 were malignant melanoma of unspecified site of skin. A total of 333 cases of lip cancer (code ICD-X C00) were also considered in the same period.

\section{Ecological covariates}

Information on material deprivation index, altitude and solar irradiation have been collected for ecological regression analysis. The variables used for the construction of deprivation index derived from the files of the provincial population census in 1991 (http:/www.istat.it/ it/archivio/104317). In particular, for each municipality we considered the low education rate (elementary school or below), unemployment rate and the household-crowding index. The index of material deprivation was constructed, in agreement with the epidemiological literature existing in the argument (Costa et al., 2009), by adding the z-scores for each of the three variables and for each municipality. Information on the altitude of municipalities was retrieved from ISTAT (www.istat.it). The variable was transformed into a z-score before being used in the analysis.

Information on solar irradiation was collected from the Italian Agency for New Technologies, Energy and Sustainable Economic Development ENEA (http://clisun.casaccia.enea.it/Pagine/Tabelle Radiazione.htm). The information is available for 42 of the 219 municipalities. For each municipality with missing data, we replaced the missing value with the average of the predicted values for adjacent municipalities as obtained from a regression model scheme (Besag et al., 1991; Tanner and Wong, 1987).

\section{Materials and Methods}

\section{Descriptive analysis}

For each health company (ASS) of residence and separately for males and females, crude rates and age specific rates, standardised direct rates on theoretical European population and the standardised incidence ratios (SIR) using as reference the regional average rates were calculated for the period 1995-2005. For each of the 219 municipalities the risk was estimated as observed/expected. Expected cases were calculated using internal indirect standardisation and considering 18 age classes: $0-4,5-9 . .85$.

Pearl and Scott (1986) introduced the relative tumour density (RTD) measure in order to create a standard way of comparing melanomas by anatomical sites. We consider RTD defined as the standardised rate of cutaneous malignant melanoma on a given body localisation divided by the fraction of the total body area occupied by the given localisation.

\section{Bayesian hierarchical spatial models}

In order to stabilise SIRs, we used the Poisson Gamma (PG) model (Clayton and Kaldor, 1987) and the Besag York and Mollié (BYM) model (Besag et al., 1991).

We assume that the number of observed cases in the i-th municipality $(\mathrm{i}=1 \ldots 219) \mathrm{O}_{\mathrm{i}}$ follows a Poisson distribution with mean $\mathrm{E}_{\mathrm{i}} \theta_{\mathrm{i}}$, where $\mathrm{E}_{\mathrm{i}}$ is the number of expected cases with internal indirect standardisation and $\theta_{\mathrm{i}}$ is the Bayesian estimate of the relative risk (BIR):

$$
0_{\mathrm{i}} \mid \vartheta_{\mathrm{i}} \mathrm{E}_{\mathrm{i}} \propto \operatorname{Poisson}\left(\vartheta_{\mathrm{i}} \mathrm{E}_{\mathrm{i}}\right)
$$

The PG model stabilises the estimates of the relative risk (RR) through the regional mean by assuming a Gamma $(\kappa, v)$ prior distribution $\theta_{\mathrm{i}}$ where $k$ and $v$ follow an exponential distribution.

The BYM model assumes a log-linear model for the RR:

$$
\log \left(\vartheta_{i}\right)=\alpha+\mu_{i}+v_{i}
$$

where $\alpha$ is an a priori flat intercept, $\mu_{\mathrm{i}}$ is the heterogeneity random 
term which capture spatially unstructured overdispersion, $v_{i}$ is the clustering random term that capture the spatially structured variability. The term $\mathrm{u}_{\mathrm{i}}$ is a priori distributed as a Gaussian $(0,1000)$ whilst $v_{i}$ followed and intrinsic conditional autoregressive ICAR model (Besag, 1974).

That is, conditionally on $\mathrm{v}_{\mathrm{l} \sim \mathrm{i}}$ terms $(\sim \mathrm{i}$ indicates areas adjacent to $\mathrm{i}$ th ones, $\mathrm{l}=1, \ldots, 184)$, vi, is distributed as Normal $\left(\bar{v}_{i}, \lambda_{\mathrm{vi}}\right)$ where

\section{$\bar{v}_{i}=\sum_{i-i} \frac{v_{t}}{n_{i}}$ with precision $\lambda_{\text {vi }}$}

The BYM model stabiles the RR both towards the general and the local mean.

\section{Shared model}

Data on melanoma and lip cancer in men were analysed using a shared component model (Held et al., 2005). The geographic variation of the relative risks is divided into two components $f$ and $y_{\mathrm{k}}$ : the first is the shared component and the second is an additional component for the residual variation, specific to melanoma. In particular, we assume that:

$$
O_{i k} \mid \vartheta_{i k} E_{i k} \propto \operatorname{Poisson}\left(\vartheta_{i k} E_{i k}\right)
$$

where, $\mathrm{O}_{\mathrm{ik}}$ are the observed cases for the $\mathrm{i}$-th area and the $\mathrm{k}$-th disease ( $\mathrm{k}=1$ indexes the melanoma, $\mathrm{k}=2$ the lip cancer). We assume a log-linear model for the relative risk of the two diseases:

$$
\begin{gathered}
\log \left(\vartheta_{i 1}\right)=\alpha_{1}+\delta \varphi_{i}+\varphi_{i 1} \\
\log \left(\vartheta_{i 2}\right)=\alpha_{2}+\varphi_{i}+\delta
\end{gathered}
$$

where $\alpha_{k}$ is a disease specific intercept representing the relative risk of disease in the $\mathrm{k}$-th region, $\delta$ is a scaling factor, $\varphi$ is the random term of clustering shared between the two diseases with conditional autoregressive distribution CAR and $\varphi_{i 1}$ is the specific component for melanoma.

In all models, the posterior probability is estimated by MCMC algorithms through WinBugs1.4 software (Lunn et al., 2000).

In the results section we reported maps of raw and smoothed Bayesian RR and posterior probabilities to be in excess respect to the regional mean choosing a threshold of $80 \%$ to be protected against false negatives (Richardson et al., 2004).

\section{Ecological regression models}

We adapted three BYM Bayesian ecological regression models in which we alternatively included as covariates the deprivation index, altitude and solar radiation. The BYM model becomes:

$$
\log \left(\vartheta_{i}\right)=\mu_{i}+v_{i}+\beta \times \operatorname{cov}_{i}
$$

where $\beta$ is the regression coefficient assumed a priori weakly informative.

We also adapted the three models without the clustering random terms to explore presence of spatial confounding (Catelan et al., 2009; Hughes and Haran, 2013)

\section{Results}

In Table 1, we report, by health centre (ASS), crude rates, standardised rates and SIR for cutaneous melanoma for the period 1995 to 2005 in FVG. There is a high variability with SIR values ranging between 1.40 and 0.59 in men and between 1.25 and 0.80 in women. Higher risks are present in the coastal area (ASS1, ASS2 and ASS5) than in the inner zone (ASS4 and ASS6) and the mountain area (ASS3). Figure 1 reports the spatial distribution of raw SIR by municipalities. Figure $2 \mathrm{~A}$ and $3 \mathrm{~A}$ represent Bayesian relative risks (BIR) under the PoissonGamma model and BYM model respectively. Figures $2 \mathrm{~B}$ and $3 \mathrm{~B}$ report, for each municipality, the posterior probability to be in excess respect to the regional mean under the two models. The spatial pattern is clear, with higher risk in the coastal area and lower in the central and mountain area. The extent of spatial clustering can be appreciated from Table 2 in which we report the two components of the BYM model (clustering and heterogeneity) and their ratio. Age-specific rate curves for men are shown in Figure 4 (A). The trend showed an increased risk for people resident in Trieste, particularly in the younger age classes. Among the older, the coastal area showed the highest values. The same curves for women are reported in Figure 4 (B): the area of Trieste showed the highest values in age classes $>60 \mathrm{yrs}$.

In Table 3 we report the crude rates, standardised rates and SIR, by ASS, for lip cancer from 1995 to 2005 in FVG. There is a high variability with SIR values ranging between 1.84 and 0.58 in men and between 2.04 and 0.48 in women.

\section{Results for the shared model}

Figure 5 reports the spatial shared and specific random terms for lip cancer and cutaneous melanoma in males in the period 1995-2005 in

\begin{tabular}{|c|c|c|c|c|c|c|c|c|}
\hline \multirow[t]{2}{*}{ ASS } & \multicolumn{3}{|c|}{ Male } & \multirow[b]{2}{*}{ SIR } & \multirow[b]{2}{*}{ Cases } & \multicolumn{3}{|c|}{ Female } \\
\hline & Cases & Crude rate & Standardised rate ${ }^{\circ}$ & & & Crude rate & Standardised rate $^{\circ}$ & SIR \\
\hline ASS 1 (Triestina) & 355 & 28.45 & 19.67 & 1.40 & 340 & 24.00 & 18.40 & 1.25 \\
\hline ASS 2 (Isontina) & 175 & 24.23 & 18.44 & 1.28 & 160 & 20.53 & 15.52 & 1.11 \\
\hline ASS 3 (Alto Friuli) & 44 & 10.84 & 8.36 & 0.59 & 68 & 15.80 & 11.09 & 0.88 \\
\hline ASS 4 (Medio Friuli) & 288 & 16.24 & 12.74 & 0.88 & 321 & 16.62 & 12.54 & 0.93 \\
\hline ASS 5 (Bassa Fiulana) & 100 & 17.54 & 13.83 & 0.96 & 111 & 18.62 & 13.48 & 1.06 \\
\hline ASS 6 (Friuli Occidentale) & 199 & 12.93 & 10.65 & 0.75 & 222 & 13.80 & 10.25 & 0.80 \\
\hline Total & 1161 & 18.55 & 14.23 & 1.00 & 1222 & 18.07 & 13.51 & 1.00 \\
\hline
\end{tabular}
FVG. The shared component highlighted west and south part of the

Table 1. Number of cases, crude and standardised rate, and standardised incidence ratio for cutaneous melanoma in Friuli Venezia Giulia (1995-2005), by gender.

ASS, azienda per l'assistenza sanitaria (healthcare assistance company); SIR, standardised incidence ratio. ${ }^{\circ}$ Direct standardisation on European population. 
region while the specific component of melanoma the coastal area and Trieste. The estimate of the $\delta$ parameter is 0.45 (95\% CrI $0.28,0.65)$ suggesting that the unobserved risk factors shared by the two diseases are more associated with lip cancer than melanoma.

\section{Ecological regression models}

Table 4 shows the maximum, median and minimum values for covariates considered, by ASS in FVG. In Figure 6, we reported the spatial distribution of the three covariates in the region. Incidence of cutaneous melanoma (Figure 2) and altitude exhibit a completely different spatial distribution, while is similar with that of solar radiation. More confusing is the relationship with material deprivation. The solar irradiation distribution by municipalities was obtained by means of a Bayesian model, while for other covariates we have empirical data for each municipality. The results of the ecological regression models are shown in Table 5. A modest inverse association is observed with the material deprivation index $(-0.048 ; 95 \% \mathrm{CrI}:-0.02 ; 0.04)$. The results are consistent in both models with and without the clustering random term. Altitude and irradiation have a spatial structure, which is strongly related to the geographical distribution of cutaneous melanoma leading to over-adjustment when the clustering term is in the model. The results of the models without clustering showed a decreased risk of $15 \%$ for one standard deviation above sea level, and an increase of $5 \%$ for unit of standard deviation in solar irradiation.

\section{Results by site}

We focused on the analysis of standardised rates per unit of body surface area and on the relative tumour density (RTD), by dividing the incident cases of melanoma by site, separately for 3 different areas: area of Trieste (ASS1), coastal area (ASS2 and ASS5) and the rest of the region (ASS3, ASS4 and ASS6).

Table 6 shows, separately by sex and by area, the percentage of body surface area, the standardised rate, the standardised rate per unit area and the relative tumour density in the locations considered.

Table 2. Standard deviation of the two random terms of Besag York and Mollié model, heterogeneity and clustering, reporting incidence of cutaneous melanoma in Friuli Venezia Giulia (1995-2005).

\begin{tabular}{|c|c|c|c|c|c|c|}
\hline & \multicolumn{2}{|c|}{ Total } & \multicolumn{2}{|c|}{ 0-64 years } & \multicolumn{2}{|c|}{$65+$ vears } \\
\hline & Male & Female & Male & Female & Male & Female \\
\hline Heterogeneity (SD) & $0.08(0.05)$ & $0.11(0.06)$ & $0.12(0.06)$ & $0.12(0.07)$ & $0.07(0.04)$ & $0.10(0.06)$ \\
\hline Clustering (SD) & $0.31(0.08)$ & $0.17(0.07)$ & $0.42(0.12)$ & $0.28(0.10)$ & $0.28(0.10)$ & $0.12(0.08)$ \\
\hline Ratio (clustering/heterogeneity) & 3.9 & 1.5 & 3.5 & 2.3 & 4.0 & 1.2 \\
\hline
\end{tabular}

SD, standard deviation.

Table 3. Number of cases, crude and standardised rate, and standardised incidence ratio for lip cancer in Friuli Venezia Giulia (19952005), by gender.

\begin{tabular}{|c|c|c|c|c|c|c|c|c|}
\hline \multirow[t]{2}{*}{ ASS } & \multicolumn{3}{|c|}{ Male } & \multirow[b]{2}{*}{ SIR } & \multirow[b]{2}{*}{ Cases } & \multirow[b]{2}{*}{ Crude rate } & \multicolumn{2}{|l|}{ Female } \\
\hline & Cases & Crude rate & Standardised rate ${ }^{\circ}$ & & & & Standardised rate ${ }^{\circ}$ & SIR \\
\hline ASS 1 (Triestina) & 35 & 2.80 & 1.60 & 0.58 & 9 & 0.64 & 0.19 & 0.48 \\
\hline ASS 2 (Isontina) & 45 & 6.23 & 3.98 & 1.47 & 13 & 1.67 & 0.73 & 1.45 \\
\hline ASS 3 (Alto Friuli) & 12 & 2.96 & 2.24 & 0.75 & 3 & 0.70 & 0.16 & 0.60 \\
\hline ASS 4 (Medio Friuli) & 57 & 3.21 & 2.14 & 0.80 & 15 & 0.78 & 0.25 & 0.74 \\
\hline ASS 5 (Bassa Fiulana) & 42 & 7.37 & 4.90 & 1.84 & 12 & 2.01 & 0.72 & 2.04 \\
\hline ASS 6 (Friuli Occidentale) & 67 & 4.35 & 3.20 & 1.18 & 23 & 1.43 & 0.60 & 1.43 \\
\hline Total & 258 & 4.12 & 2.71 & 1.00 & 75 & 1.11 & 0.40 & 1.00 \\
\hline
\end{tabular}

ASS, azienda per l'assistenza sanitaria (healthcare assistance company); SIR, standardised incidence ratio. ${ }^{\circ}$ Direct standardisation on European population.

Table 4. Maximum, median and minimum values of covariates included in the ecologic regression: altitude, material deprivation index, solar irradiation (average values, 1994-1999).

\begin{tabular}{|c|c|c|c|c|c|c|c|c|c|}
\hline \multirow[t]{2}{*}{ ASS } & \multicolumn{3}{|c|}{ Altitude (m) } & \multicolumn{3}{|c|}{ Deprivation (z) } & \multicolumn{3}{|c|}{ Irradiation $\left(\mathrm{Mj} / \mathrm{m}^{2}\right)$} \\
\hline & Max & Median & Min & Max & Median & Min & Max & Median & Min \\
\hline ASS 1 (Triestina) & 418 & 125 & 2 & 0.39 & -1.41 & -2.04 & 4834 & 4819 & 4806 \\
\hline ASS 2 (Isontina) & 276 & 32 & 2 & 3.17 & -0.63 & -2.21 & 4869 & 4783 & 4751 \\
\hline ASS 3 (Alto Friuli) & 1400 & 492 & 184 & 7.9 & 0.83 & -2.02 & 4885 & 4804 & 4691 \\
\hline ASS 4 (Medio Friuli) & 663 & 135 & 18 & 3.66 & -0.71 & -2.76 & 4836 & 4726 & 4594 \\
\hline ASS 5 (Bassa Fiulana) & 43 & 9 & 2 & 3.85 & 0.59 & -1.82 & 4829 & 4736 & 4669 \\
\hline ASS 6 (Friuli Occidentale) & 830 & 116 & 11 & 3.42 & -0.13 & -2.9 & 4856 & 4808 & 4718 \\
\hline Total & 1400 & 113 & 2 & 7.9 & -0.26 & -2.9 & 4885 & 4799 & 4594 \\
\hline
\end{tabular}

ASS, azienda per l'assistenza sanitaria (healthcare assistance company). 
A

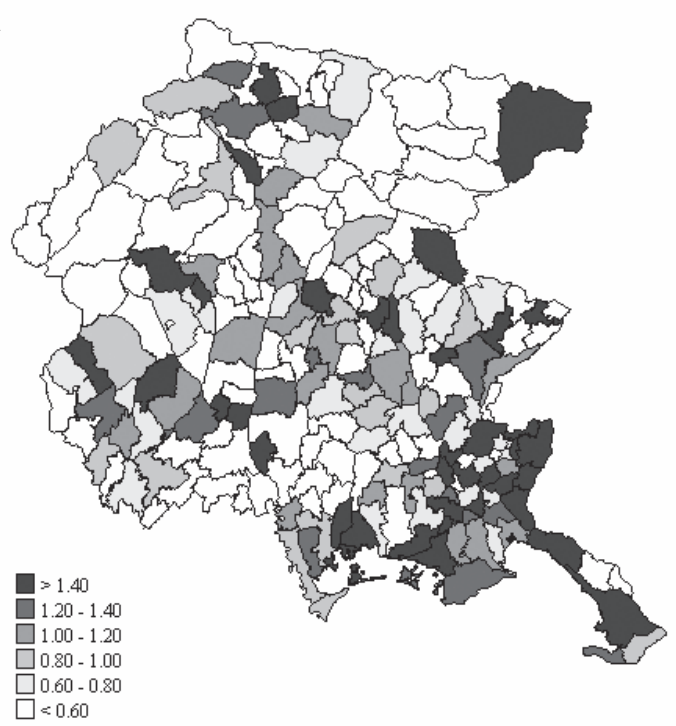

B

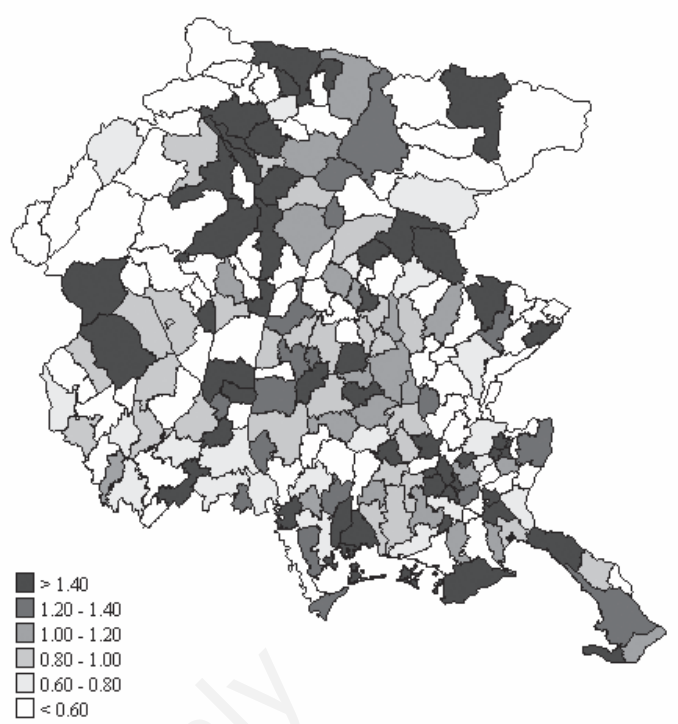

Figure 1. Standardised incidence ratio of males (A and females (B) by municipalities in Friuli Venezia Giulia (1995-2005).

A

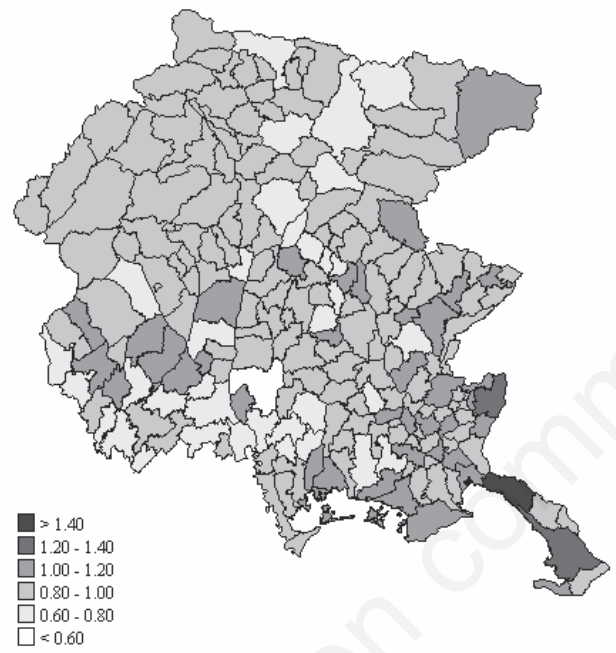

C

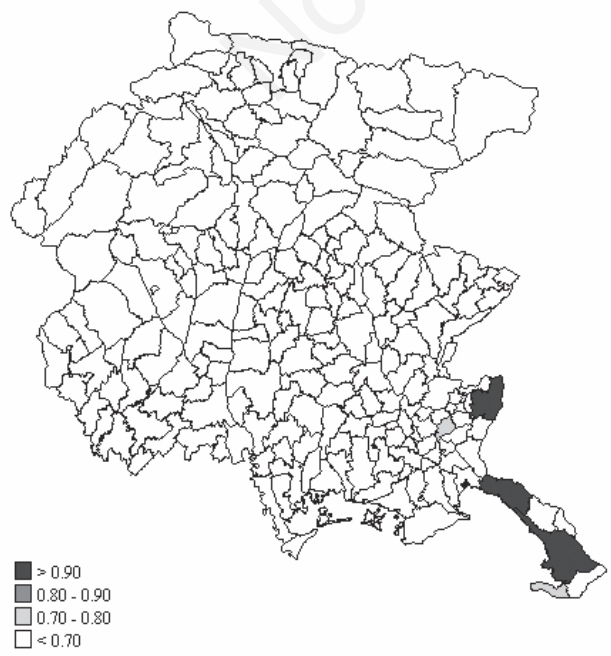

B

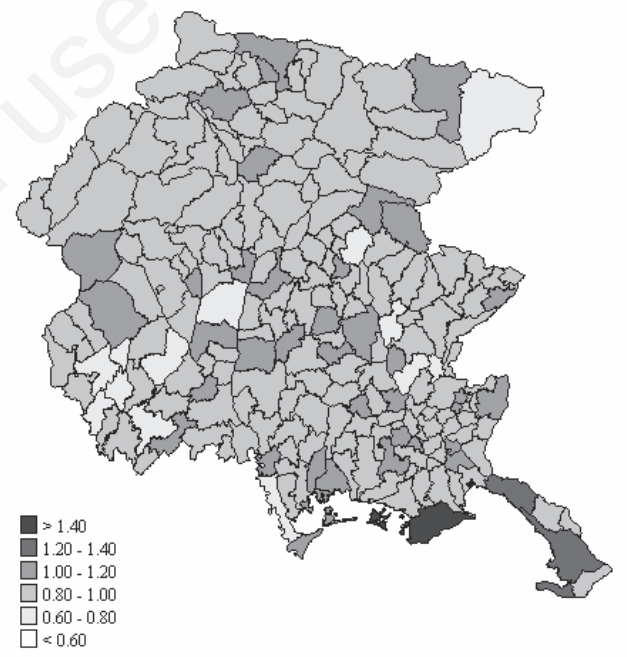

D

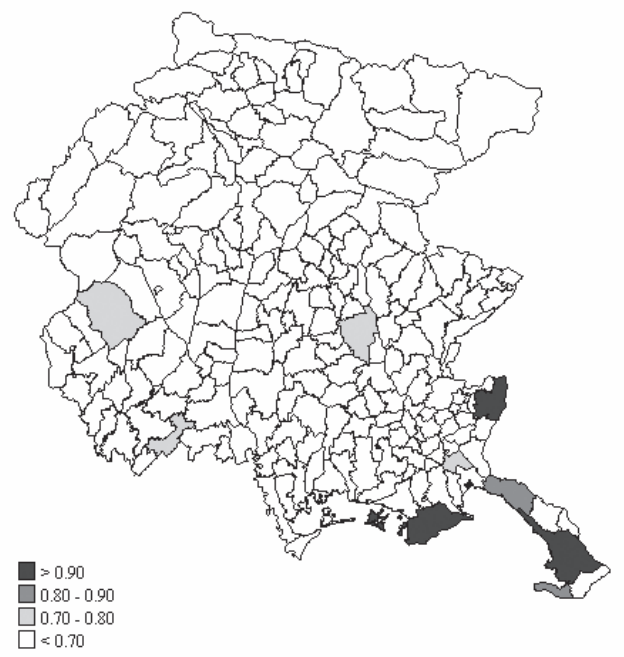

Figure 2. A, B) Bayesian relative risks by municipality; C, D) Bayesian posterior probabilities of each municipality to be in excess with respect to the regional mean. Values for males are in A) and C), and for females in B) and D). Poisson-Gamma model. Friuli Venezia Giulia (1995-2005). 
In males, the standardised rate is around 18 per 100,000 for both Trieste and the coastal area, while it is around 10 per 100,000 in the rest of the region. The distribution by site, however, is very different: in the area of Trieste is the trunk to show the highest rate (33 per 100,000 unit area with RTD 1.78), while in the coastal area is the face (152 per 100,000 unit area with RTD 8.45). In women, the standardised rate is around 18 per 100,000 in the area of Trieste, while the rest of the region has values around $10 / 12$ per 100,000 . The distribution by site is very different: in the area of Trieste is still the trunk to show the highest rates per unit area (22 per 100,000 units of surface and RTD 1.28) against high values (between 18 and 26 per 100,000 units of surface with RTD between 1.7 and 2.4) for the face in the remaining areas.

Table 7 shows the analysis of the relative tumour density by site and age $(<50,50-64,65+$ years). In men, trunk show higher values in younger age groups in all areas. On the other hand, the face tends to show very high values of RTD in the older age classes, especially in coastal and mountain areas. In women, we find the trunk with a high RTD at a young age, the upper and lower limbs in old age in the area of Trieste. In the coastal area, as in Trieste, upper and lower limbs in old age show high RTD, and face with high RTD. In the remaining area, only the face shows high values of RTD, in old age.

Table 5. Regression coefficients with $90 \%$ credible interval, with and without clustering in Friuli Venezia Giulia (1995-2005).

\begin{tabular}{lll} 
& With clustering & Without clustering \\
Irradiation & $-0.208(-0.42,-0.11)$ & $0.046(0.0001,0.14)$ \\
Deprivation & $-0.048(-0.02,0.04)$ & $-0.0578(-0.02,0.01)$ \\
\hline Altitude & $-0.047(-0.04,0.04)$ & $-0.171(-0.26,-0.11)$ \\
\hline
\end{tabular}

B

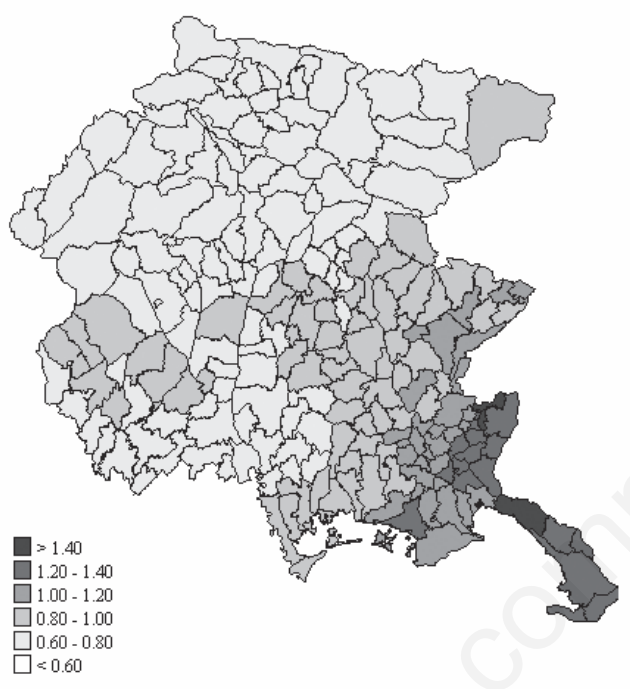

C

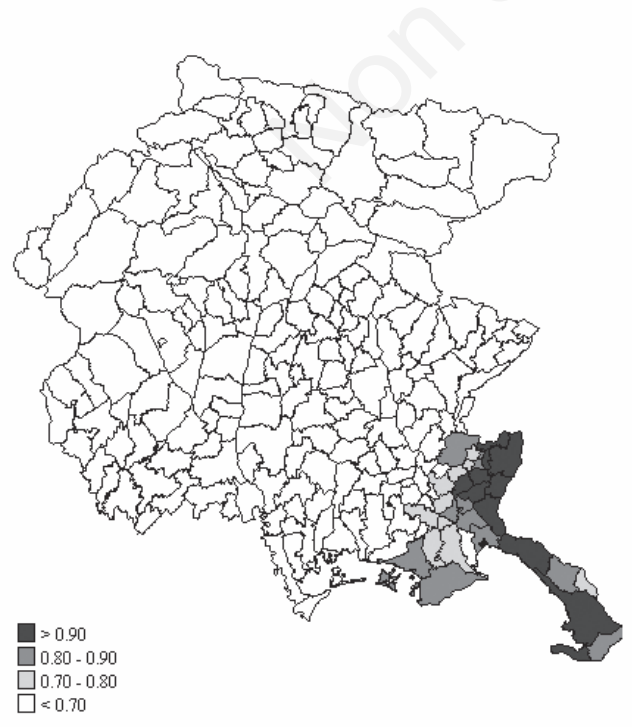

D

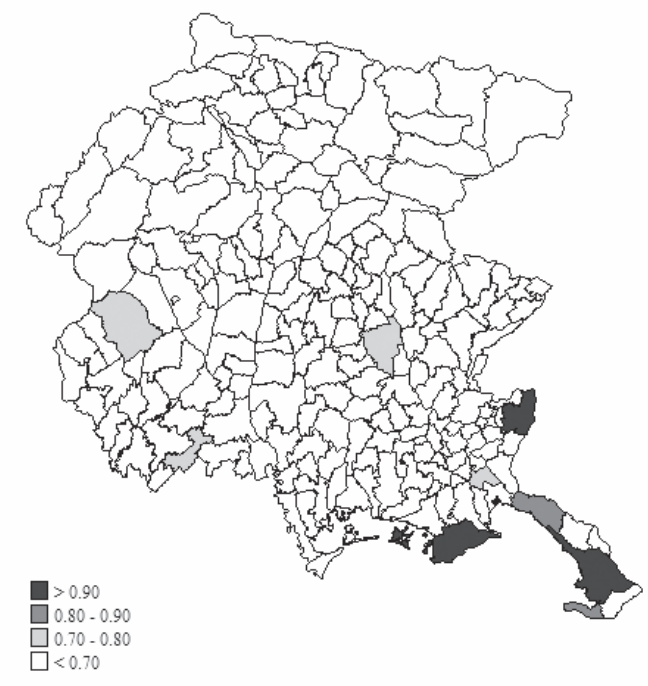

Figure 3. A, B) Bayesian relative risks by municipality; C, D) Bayesian posterior probabilities of each municipality to be in excess with respect to the regional mean. Values for males are in A) and C), and for females in B) and D). Besag York and Mollié model. Friuli Venezia Giulia (1995-2005). 
Table 6. Standardised rates, standardised rates per unit of body surface, relative tumour density by site of cutaneous melanoma, separately by gender and areas in Friuli Venezia Giulia (1995-2005).

\begin{tabular}{|c|c|c|c|c|c|c|}
\hline ASS & Gender & Sites & $\begin{array}{c}\text { Body } \\
\text { surface (\%) }\end{array}$ & $\begin{array}{l}\text { Standardised } \\
\text { rates }\end{array}$ & $\begin{array}{c}\text { Standardised } \\
\text { rates per unit of body surface }\end{array}$ & RTD \\
\hline ASS 1 & Male & $\begin{array}{l}\text { Face } \\
\text { Ears } \\
\text { Scalp, neck } \\
\text { Trunk } \\
\text { Upper } \\
\text { Lower } \\
\text { Total }\end{array}$ & $\begin{array}{l}2.9 \\
0.6 \\
5.5 \\
32 \\
19 \\
40\end{array}$ & $\begin{array}{c}0.62 \\
0.07 \\
1.08 \\
10.57 \\
3.74 \\
2.45 \\
18.52\end{array}$ & $\begin{array}{l}21.23 \\
12.46 \\
19.59 \\
33.02 \\
19.68 \\
6.13\end{array}$ & $\begin{array}{l}1.15 \\
0.67 \\
1.06 \\
1.78 \\
1.06 \\
0.33\end{array}$ \\
\hline & Female & $\begin{array}{l}\text { Face } \\
\text { Ears } \\
\text { Scalp, neck } \\
\text { Trunk } \\
\text { Upper } \\
\text { Lower } \\
\text { Total }\end{array}$ & $\begin{array}{l}2.9 \\
0.6 \\
5.5 \\
32 \\
19 \\
40\end{array}$ & $\begin{array}{c}0.37 \\
0.05 \\
0.71 \\
7.00 \\
3.92 \\
7.30 \\
17.02\end{array}$ & $\begin{array}{l}12.67 \\
7.57 \\
12.87 \\
21.87 \\
20.62 \\
18.25\end{array}$ & $\begin{array}{l}0.74 \\
0.44 \\
0.76 \\
1.28 \\
1.21 \\
1.07\end{array}$ \\
\hline ASS 2, ASS 5 & Male & $\begin{array}{l}\text { Face } \\
\text { Ears } \\
\text { Scalp, neck } \\
\text { Trunk } \\
\text { Upper } \\
\text { Lower } \\
\text { Total }\end{array}$ & $\begin{array}{l}2.9 \\
0.6 \\
5.5 \\
32 \\
19 \\
40\end{array}$ & $\begin{array}{c}4.43 \\
0.18 \\
1.11 \\
7.71 \\
2.32 \\
2.32 \\
18.06\end{array}$ & $\begin{array}{c}152.62 \\
29.79 \\
20.26 \\
24.10 \\
12.16 \\
5.80\end{array}$ & $\begin{array}{l}8.45 \\
1.65 \\
1.12 \\
1.33 \\
0.67 \\
0.32\end{array}$ \\
\hline & Female & $\begin{array}{l}\text { Face } \\
\text { Ears } \\
\text { Scalp, neck } \\
\text { Trunk } \\
\text { Upper } \\
\text { Lower } \\
\text { Total }\end{array}$ & $\begin{array}{l}2.9 \\
0.6 \\
5.5 \\
32 \\
19 \\
40\end{array}$ & $\begin{array}{c}0.74 \\
0.07 \\
0.46 \\
1.38 \\
3.15 \\
5.99 \\
12.58\end{array}$ & $\begin{array}{l}25.52 \\
11.67 \\
8.36 \\
4.32 \\
16.58 \\
14.98\end{array}$ & $\begin{array}{l}2.03 \\
0.93 \\
0.66 \\
0.34 \\
1.32 \\
1.19\end{array}$ \\
\hline ASS 3, ASS 4, ASS 6 & Male & $\begin{array}{l}\text { Face } \\
\text { Ears } \\
\text { Scalp, neck } \\
\text { Trunk } \\
\text { Upper } \\
\text { Lower } \\
\text { Total }\end{array}$ & $\begin{array}{l}2.9 \\
0.6 \\
5.5 \\
32 \\
19 \\
40\end{array}$ & $\begin{array}{c}0.71 \\
0.07 \\
0.81 \\
5.63 \\
1.64 \\
1.33 \\
10.15\end{array}$ & $\begin{array}{l}24.56 \\
11.32 \\
14.67 \\
17.61 \\
8.63 \\
3.33\end{array}$ & $\begin{array}{l}2.42 \\
1.11 \\
1.45 \\
1.73 \\
0.85 \\
0.33\end{array}$ \\
\hline & Female & $\begin{array}{l}\text { Face } \\
\text { Ears } \\
\text { Scalp, neck } \\
\text { Trunk } \\
\text { Upper } \\
\text { Lower } \\
\text { Total }\end{array}$ & $\begin{array}{l}2.9 \\
0.6 \\
5.5 \\
32 \\
19 \\
40\end{array}$ & $\begin{array}{c}0.52 \\
0.07 \\
0.22 \\
3.16 \\
2.12 \\
4.41 \\
10.49\end{array}$ & $\begin{array}{c}17.79 \\
10.86 \\
4.06 \\
9.86 \\
11.15 \\
11.04\end{array}$ & $\begin{array}{l}1.70 \\
1.03 \\
0.39 \\
0.94 \\
1.06 \\
1.05\end{array}$ \\
\hline
\end{tabular}

ASS 1, Trieste; ASS 2,5, coastal area; ASS 3,4,6, other; RTD, relative tumour density.

Table 7. Relative tumour density by sites, separately by gender, areas and age, in Friuli Venezia Giulia (1995-2005).

\begin{tabular}{|c|c|c|c|c|c|c|c|}
\hline ASS & Sites & $<50$ years & $\begin{array}{c}\text { Male } \\
\text { 50-64 years }\end{array}$ & $65+$ years & $<50$ years & $\begin{array}{c}\text { Female } \\
\text { 50-64 years }\end{array}$ & $65+$ years \\
\hline ASS 1 & $\begin{array}{l}\text { Face } \\
\text { Scalp, neck } \\
\text { Trunk } \\
\text { Upper } \\
\text { Lower }\end{array}$ & $\begin{array}{l}1.9 \\
0.5 \\
1.8 \\
0.9 \\
0.4\end{array}$ & $\begin{array}{l}0.3 \\
1.2 \\
1.8 \\
1.1 \\
0.3\end{array}$ & $\begin{array}{l}1.3 \\
1.3 \\
1.7 \\
1.1 \\
0.3\end{array}$ & $\begin{array}{l}0.0 \\
0.8 \\
1.5 \\
1.0 \\
0.9\end{array}$ & $\begin{array}{l}1.1 \\
0.4 \\
1.2 \\
1.3 \\
1.0\end{array}$ & $\begin{array}{l}2.1 \\
1.2 \\
0.9 \\
1.6 \\
1.7\end{array}$ \\
\hline ASS 2, ASS 5 & $\begin{array}{l}\text { Face } \\
\text { Scalp, neck } \\
\text { Trunk } \\
\text { Upper } \\
\text { Lower }\end{array}$ & $\begin{array}{l}3.7 \\
0.8 \\
1.7 \\
0.7 \\
0.4\end{array}$ & $\begin{array}{l}8.2 \\
0.5 \\
1.2 \\
0.8 \\
0.3\end{array}$ & $\begin{array}{l}9.9 \\
2.1 \\
1.1 \\
0.5 \\
0.2\end{array}$ & $\begin{array}{l}0.7 \\
0.5 \\
0.4 \\
1.0 \\
1.1\end{array}$ & $\begin{array}{l}0.4 \\
0.7 \\
0.3 \\
1.4 \\
1.0\end{array}$ & $\begin{array}{l}5.3 \\
0.8 \\
0.2 \\
1.8 \\
1.5 \\
\end{array}$ \\
\hline ASS 3, ASS 4, ASS 6 & $\begin{array}{l}\text { Face } \\
\text { Scalp, neck } \\
\text { Trunk } \\
\text { Upper } \\
\text { Lower }\end{array}$ & $\begin{array}{l}0.4 \\
1.4 \\
1.8 \\
0.8 \\
0.5\end{array}$ & $\begin{array}{l}1.5 \\
0.8 \\
1.8 \\
1.0 \\
0.2\end{array}$ & $\begin{array}{l}4.3 \\
3.5 \\
1.6 \\
0.8 \\
0.2\end{array}$ & $\begin{array}{l}1.0 \\
0.3 \\
1.2 \\
0.9 \\
1.0\end{array}$ & $\begin{array}{l}0.4 \\
0.3 \\
1.0 \\
1.3 \\
1.1\end{array}$ & $\begin{array}{l}4.0 \\
0.7 \\
0.4 \\
1.1 \\
1.2\end{array}$ \\
\hline
\end{tabular}




\section{Discussion}

The spatial distribution of the incidence of cutaneous melanoma in FVG region is very marked. The Cancer Registry has been active for many years and incompleteness of registration for selective areas of the province of Pordenone and Udine seems unlikely. In fact, the percentage of histological verification is $93 \%$ for men and $97 \%$ for women, the DCO is equal to $0 \%$ for both sexes, the ratio $\mathrm{M} / \mathrm{I}$ is 0.25 for males and 0.18 for females (Bidoli et al., 2007).

A different diagnostic assessment in the area of Trieste and in the

coastal area could lead to a more accurate recognition, while elsewhere some cases may not be recognised. An effect of screening on prevalent cases is not sustainable for a period of 11 years. In addition, the differences by ASS have been documented since the birth of cancer registry and were also present in the atlas of cancer mortality in the eighties (Bidoli et al., 1999). If a phenomenon of early diagnosis exists, this would be relative to superficial spreading type (Golger et al., 2007). In the FVG registry, however, the percentage of classified as malignant melanoma (ICD-0-3M=M8720/3) is 47.3\%, making it impossible to verify. The age-specific rate curve could involve some cohort trends. For example, among males, in Trieste, high rates for people less than fifty

A

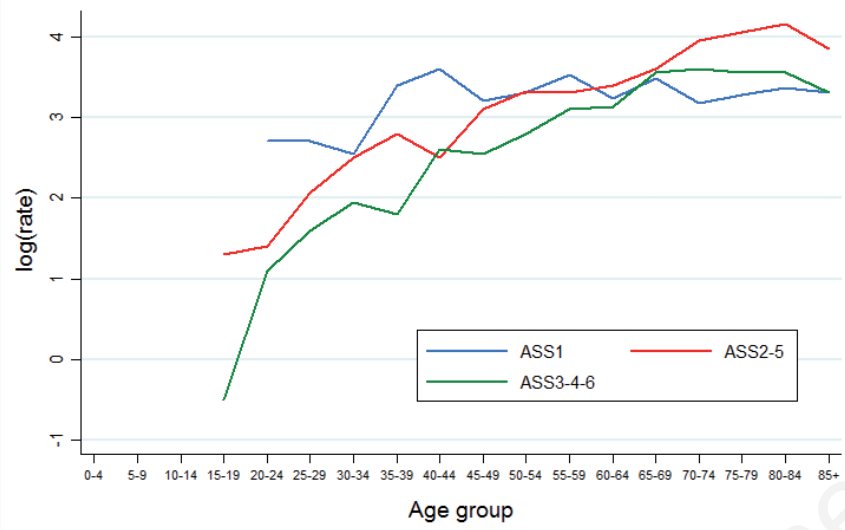

B

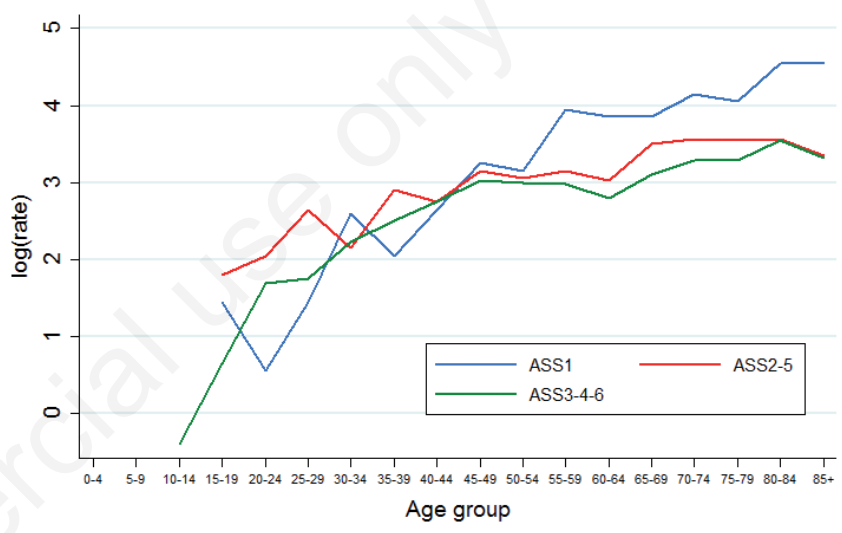

Figure 4. Age specific rate curve. Rates are on logarithmic scale. Areas are denoted respectively by 1 (Trieste), 2-5 (coastal area) and 34-6 (other). Values for males are in A) and for females in B). Friuli Venezia Giulia (1995-2005).

A

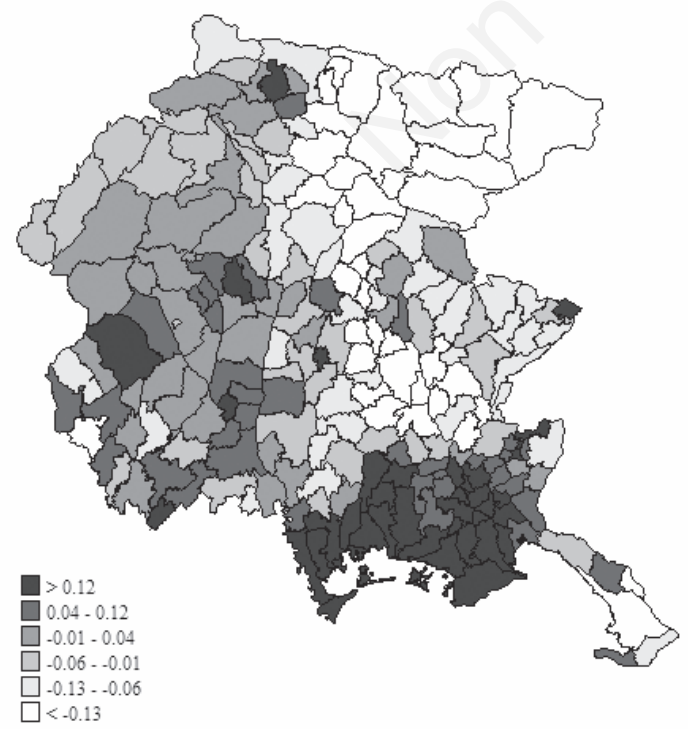

B

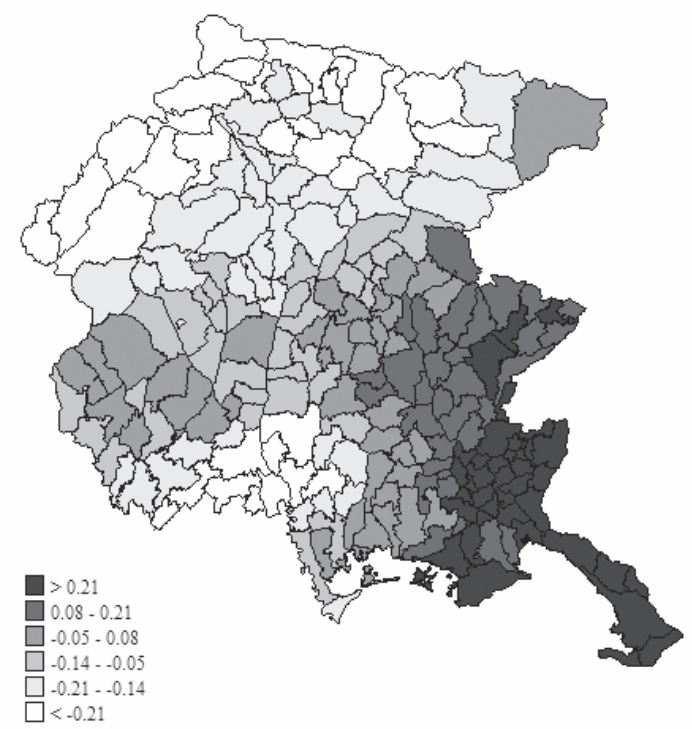

Figure 5. Shared (A) component with the lip cancer and specific (B) component of relative risk for cutaneous melanoma, by municipality. Bivariate hierarchical Bayesian model. Friuli Venezia Giulia (1995-2005). 
years old could be a symptom of a much greater risk for cohorts born after World War II that have probably been sun intermittently exposed (seaside holidays) from childhood. This may be a characteristic for the richest area in the region where occupational exposure is less prevalent. Among females, the pattern shows high rates for the Trieste population in older age groups comparing to other regional areas.

Lip cancer has been associated with occupational exposure and solar radiation (Moore et al., 1999). The shared model shows that a small portion of the spatial distribution for melanoma is explained by common factors with lip cancer. The results suggest occupational exposures in the municipalities of the coastal zone.

Ecological regression analysis shows that actually solar radiation is higher in the coastal area and in Trieste, and lesser in other areas. A work on data from the Styria cancer registry (Richting et al., 2007) reported lower incidence rates in mountain areas. The FVG data are consistent with that observation and with lower levels of solar radiation in that area.

As regards the analysis by site, the number of unspecified sites could affect it. However, for the FVG registry, this number is limited $(9.4 \%$ at regional level). In our data we do not have a detailed classification of site and it is thus not possible to split the trunk in the front, back or abdominal area, or split limbs. This leads to a certain misclassification: the back part of the trunk has typically intermittent exposures and the front part for man but not for the woman. The upper limb, the hand and wrist have a chronic exposure, while the shoulder is the most affected by intermittent exposure. The lower limb, in the woman, is typically intermittent exposed, in particular the thigh and the hip areas (Bulliard et al., 2007). The face is typical site of higher cumulative exposures, even of chronic type.

The results of the present study are very informative and consistent with the literature. Surprisingly, in the area of Trieste, the RTD for the face is close to one. The standardised rates per unit of body surface area show values among the highest in the literature, above 33 per
100,000 unit area in men and around 20 in women. The coastal area shows typical trends by site of chronic exposures .The analysis of the RTD by ages confirm these findings.

In the literature, the ear is reported as a site with high rates per unit of body surface area. The values for the coastal zone are consistent with the literature and also those of the remaining FVG areas, while they are relatively low, such as those of the rest of the face, in the area of Trieste. We do not believe they are due to a different coding assessment, but may reflect a different type of exposure.

We have not information on nevi counts in Cancer Registry datasets, therefore we cannot further speculate on the so-called divergent pathway hypothesis (Whiteman et al., 1998, 2003). However Whiteman et al. (2006) suggest divergent pathways from different exposure patterns analysing age and site-specific melanoma density distribution. A recent paper on this issue in Italy is (Chiarugi et al., 2015).

\section{Conclusions}

This study documents a significant gradient in the incidence of cutaneous melanoma in FVG region in the years 1995-2005. The area of Trieste shows very high-standardised incidence rates, around 20 per 100,000 in both sexes. High rates are present also in the coastal area, with comparable values in males. The descriptive analysis by age group and by site shows risks associated with intermittent exposures in both genders. For the coastal area the risk is especially high for sites traditionally linked to high cumulative exposures (face and neck), especially among men. From public health point of view, the results suggest diagnostic preventive interventions in the populations living in the area of Trieste, given the high rates observed in the young age groups.

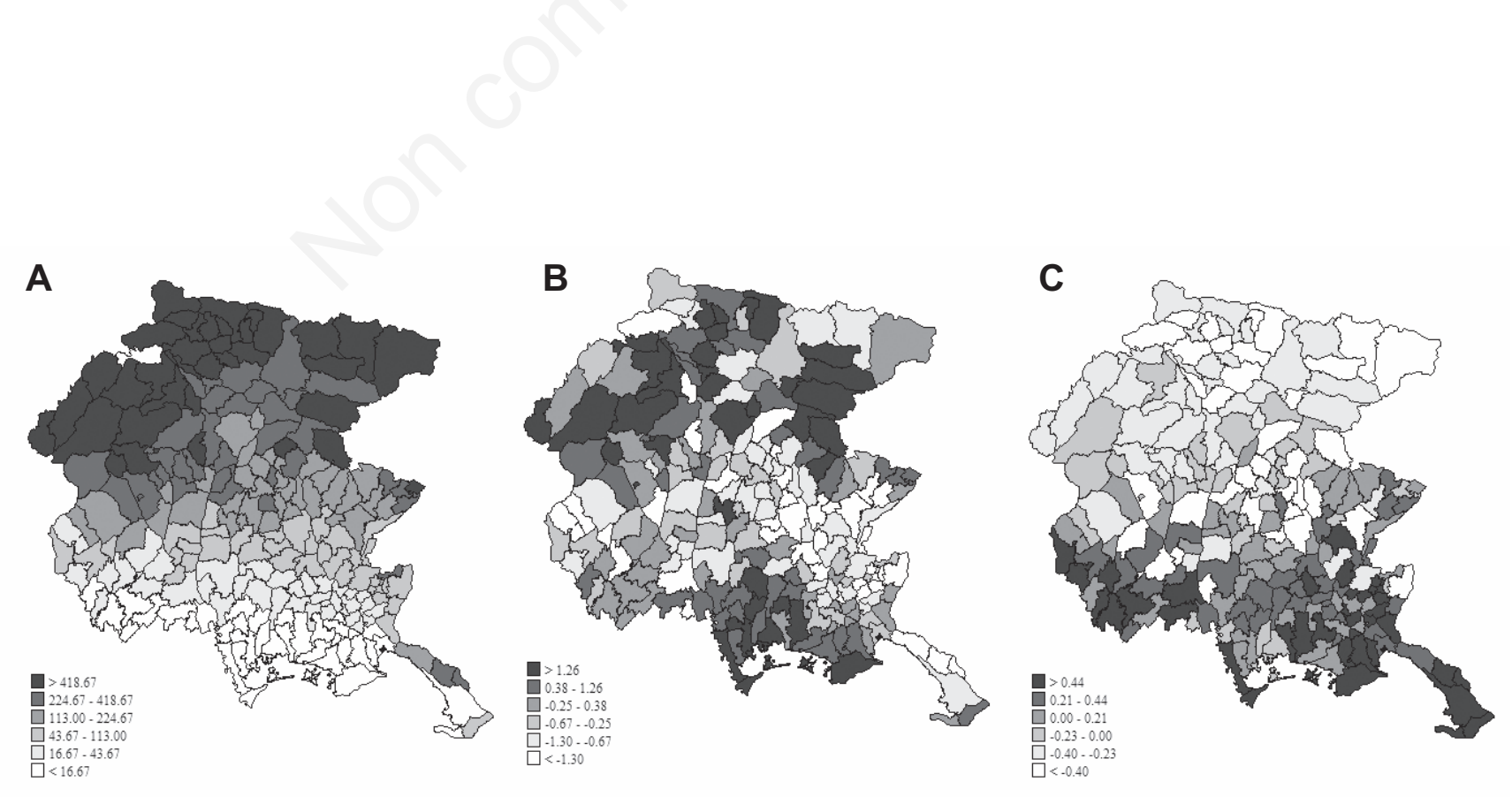

Figure 6. Spatial distribution of altitude (A), material deprivation index (B), and solar irradiation (C) in Friuli Venezia Giulia. 


\section{References}

Adami HO, Hunter D, Trichopoulos D, 2002. Textbook of cancer epidemiology. Oxford University Press, Oxford, USA.

AIRTUM Working Group, 2009. I nuovi dati di incidenza e mortalità. Periodo 2003-2005. Associazione Italiana Registri Tumori, Florence, Italy.

Armstrong BK, Kricker A, 1996. Epidemiology of sun exposure and skin cancer. Cancer Surv 26:133-53.

Besag J, 1974. Spatial interaction and the statistical analysis of lattice systems (with discussion). J Roy Stat Soc B 36:192-236.

Besag J, York JC, Mollié A, 1991. Bayesian image restoration, with two applications in spatial statistics (with discussion). Ann I Stat Math 43:1-59.

Bidoli E, 1999. Atlante della mortalità per tumori nelle regioni e province del Nord-Est e in Italia. Centro di Riferimento Oncologico, Servizio di Epidemiologia, Aviano, Italy.

Bidoli E, De Dottori M, Serraino D, Vicario G, Zanier L, 2007. Registro tumori del Friuli Venezia Giulia. Dati di incidenza 1999-2003. Centro di Riferimento Oncologico, Aviano, Italy.

Bulliard JL, 2000. Site-specific risk of cutaneous malignant melanoma and pattern of sun exposure in New Zealand. Int J Cancer 85:627-32.

Bulliard JL, Cox B, Elwood JM, 1997. Comparison of the site distribution of Melanoma in New Zealand and Canada. Int J Cancer 72:231-5.

Bulliard JL, De Weck D, Fisch T, Bordoni A, Levi F, 2007. Detailed site distribution of melanoma and sunlight exposure: aetiological patterns from a Swiss series. Ann Oncol 18:789-94.

Catelan D, Biggeri A, Lagazio C, 2009. On the clustering term in ecological analysis: how do different prior specifications affect results? Stat Method Appl 18:49-61.

Chiarugi A, Quaglino P, Crocetti E, Nardini P, De Giorgi V, Borgognoni L, Brandani P, Gerlini G, Manganoni AM, Bernengo MG, Pimpinelli N, GIPMe Centres, 2015. Melanoma density and relationship with the distribution of melanocytic naevi in an Italian population: a GIPMe study. The Italian multidisciplinary group on melanoma. Melanoma Res 25:80-7.

Clayton DG, Kaldor J, 1987. Empirical Bayes estimates of age-standardized relative risks for use in disease mapping. Biometrics 43:671-81.

Costa G, Cislaghi C, Caranci N, 2009. Le disuguaglianze sociali di salute. Problemi di definizione e di misura. Franco Angeli, Milan, Italy.

Dal H, Boldemann C, Lindelöf B, 2007. Does relative melanoma distribution by body site 1960-2004 reflect changes in intermittent exposure and intentional tanning in the Swedish population? Eur J Dermatol 17:428-34.

Franceschi S, Levi F, Randimbison L, La Vecchia C, 1996. Site distribution of different types of skin cancer: new aetiological clues.

Int J Cancer 66:1-5.

Golger A, Yoing DS, Ghazarian D, Neligan PC, 2007. Epidemiological features and prognostic factors of cutaneous head and neck melanoma: a population-based study. Arch Otolaryngol 133:442-7.

Green A, 1992. A theory of site distribution of melanoma: Queensland, Australia. Cancer Causes Control 3:513-6.

Held L, Natário I, Fenton SE, Rue H, Becker N, 2005. Towards joint disease mapping. Stat Methods Med Res 14:61-82.

Hughes J, Haran M, 2013. Dimension reduction and alleviation of confounding for spatial generalized linear mixed models. J Roy Stat Soc B 75:139-59.

Lee JAH, Merrill JM, 1970. Sunlight and the aetiology of malignant melanoma: a synthesis. Med J Australia 2:846-51.

Lunn DJ, Thomas A, Best N, Spiegelhalter D, 2000. WinBUGS. A Bayesian modelling framework: concepts, structure, and extensibility. Stat Comput 10:325-37.

Mackay J, Jemal A, Lee NC, Parkin DM, 2006. The cancer atlas. American Cancer Society, Atlanta, (GA), USA.

Maldonado JL, Fridlyand J, Patel H, Jain AN, Busam K, Kageshita T, Ono T, Albertson DG, Pinkel D, Bastian BC, 2003. Determinants of BRAF mutations in primary melanoma. J Natl Cancer I 95:1878-90.

Moore S, Johnson N, Pierce A, Wilson D, 1999. The epidemiology of lip cancer: a review of global incidence and aetiology. Oral Dis 5:185-95.

Pearl DK, Scott EL, 1986. The anatomical distribution of skin cancers. Int J Epidemiol 15:502-6.

Richardson S, Thomson A, Best N, Elliott P, 2004. Interpreting posterior relative risk estimates in disease-mapping studies. Environ Health Persp 112:1016-25.

Richtig E, Berghold A, Schwantzer G, Ott A, Wölfelmaier F, Karner B, Ludwig R, Denk H, Stering R, Leitner G, Lax S, Okcu M, Gerger A, Kerl H, Smolle J, 2007. Clinical epidemiology of invasive cutaneous malignant melanoma in the Austrian province Styria in years 20012003 and its relationship with local geographical, meteorological and economic data. Dermatology 214:246-52.

Rivers JK, 2004. Is there more than one road to melanoma? Lancet 363:728-30.

Tanner MA, Wong WH, 1987. The calculation of posterior distributions by data augmentation. J Am Stat Assoc 82:528-40.

Whiteman DC, Parsons PG, Green AC, 1998. Expression and risk factors for cutaneous melanoma: a case-control study. Int J Cancer 77:843-8.

Whiteman DC, Stickley M, Watt P, Hughes MC, Davis MB, Green AC, 2006. Anatomic site, sun exposure, and risk of cutaneous melanoma. J Clin Oncol 24:3172-7.

Whiteman DC, Watt P, Purdie DM, Hughes MC, Hayward NK, Green AC, 2003. Melanocytic nevi, solar keratoses, and divergent pathways to cutaneous melanoma. J Natl Cancer I 95:806-12. 